
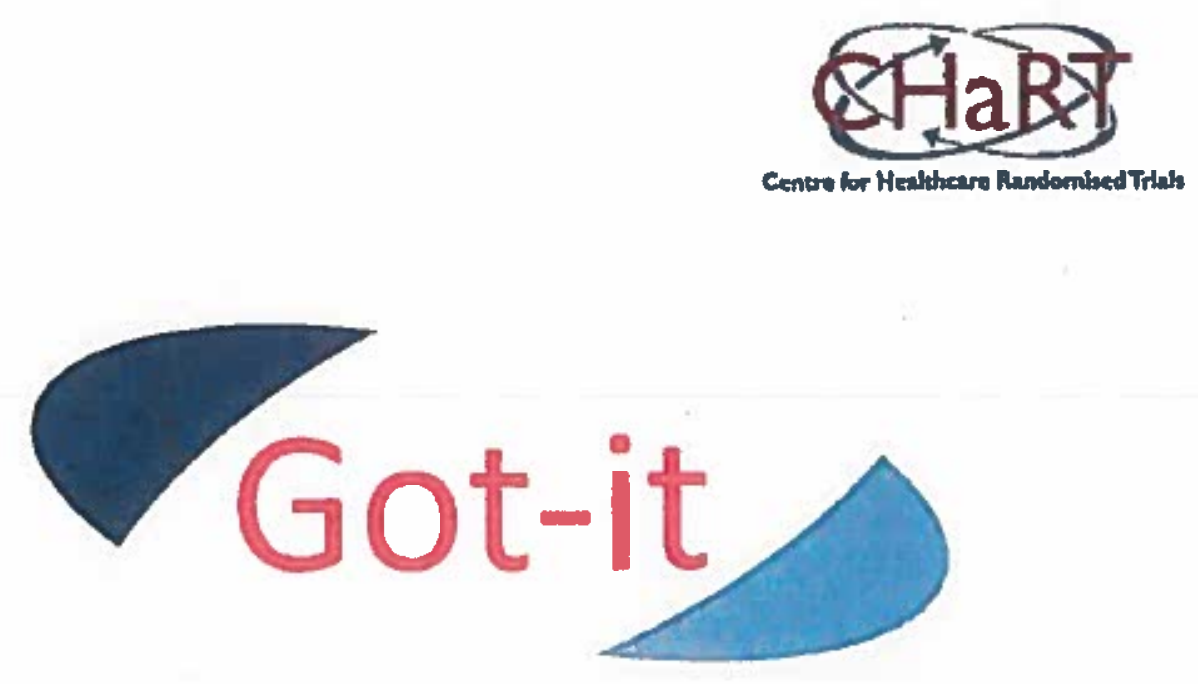

A pragmatic group sequential placebo controlled randomised trial to determine the effectiveness of Glyceryl trinitrate for retained placenta.

GOT-IT TRIAL

Glycerine trinitrate fOr reTalned placenTa

\section{Statistical Analysis Plan}

SAP Version: $\quad 1.0$

Protocol Version: 8,0

Protocol Date: $\quad 27^{\text {th }}$ April 2010

Approved by:

Dr Fiona Denison

Chief Investigntor

Prolessor Jolun Nortie Individunl Responsible for Statisticnl Review

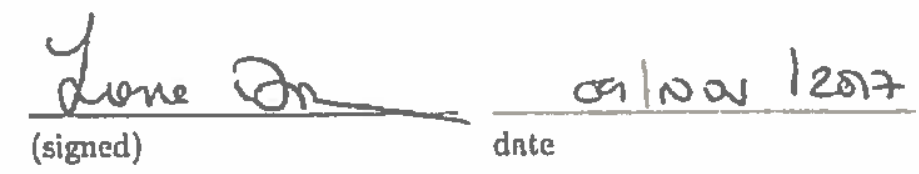

Professor Graeme MncLennnn CHaAT director
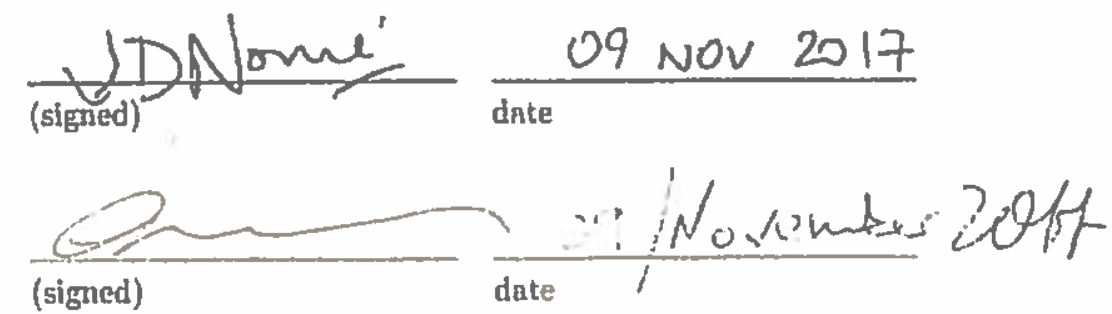



\section{Contents}

1 Study Objectives $\quad 2$

2 Study Methods $\quad 2$

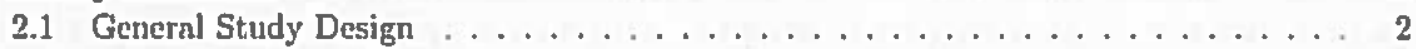

2.2 Group Sequential Design . . . . . . . . . . . . . . . . . . 2

2.3 Pnndomisation and Blinding $\ldots \ldots \ldots \ldots \ldots$

3 Outcome Measures $\quad 3$

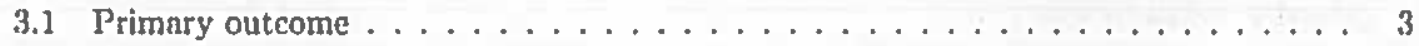

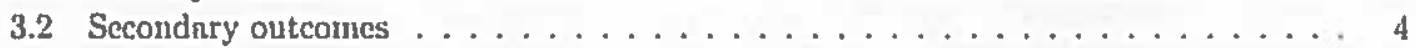

3.3 Timing of outcome mensurements ......................... 4

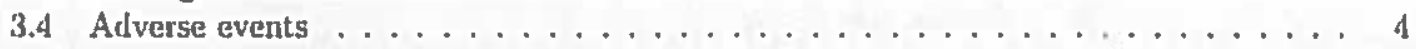

4 Sample Size and Power Calculations 5

5 Statistical Methods 5

5.1 Primary outcomes ............................ 6

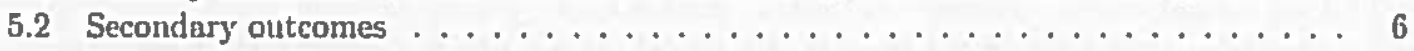

5.3 Subgroup nnalyses $\ldots \ldots \ldots \ldots \ldots$

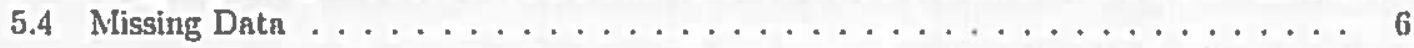

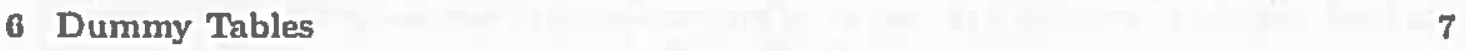

\section{List of Tables}

1 Recruitment by centre $-n(\%) \ldots \ldots \ldots \ldots \ldots$

2 Bnseline cluaracteristics . . . . . . . . . . . . . . . . . 8

3 Primary clinical outcome of need for MROP at 15 minutes post administration of

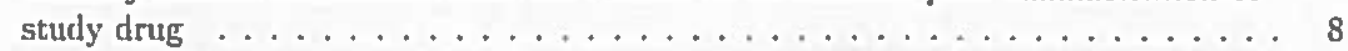

4 Primnry safety outcome of blood loss between ndministration of treatment nnd transfer to postnntal ward or other clinicnl area . . . . . . . . . . . . . . . 8

5 Primnry patient-sided outcome of sntisfaction with trentment before dischnrge and

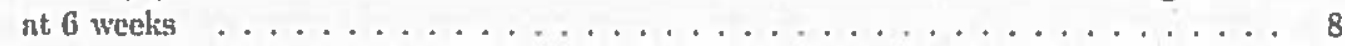

6 Primnry pntient-sided outcome of side effect profile before disclıarge nud at $\mathbf{6}$ weeks . 9

7 Secondary clinical outcomes $\ldots \ldots \ldots . \ldots \ldots$

\section{List of Figures}

$1 \quad$ Group sequential design . . . . . . . . . . . . . . . 3 


\section{Study Objectives}

The overall aim of this study is to detemine the clinical effectiveness and cost effectiveness of sublingual Glyceryl Trinitrate (GTN) sprny compared with plncebo in reducing the need for manual removal of placentn (MNOP) is women with a retnined placenta (RP) neter vaginal delivery following fnilure of current management (defined as a third stage of labour lasting more than 30 minutes after active mnnagement or $\mathbf{6 0}$ minutes after physiological followed by active management respectively).

\section{Study Methods}

\subsection{General Study Design}

There will be an internal pilot RCT, full details of which nse in the protocol. The purpose of the pilot is to provide reassurances about all of the trial processes and the results will be reported to the Data Monitoring Committee (DMC), on whose recommendation the trial will be expanded to the full study design.

GOT-IT is a randomised, placebo controlled, double-blind pragmatic trinl. Due to the sparse nature of poor qunlity data for the use of GTN lor RP, trentment and control effect rate, there is at present considerable uncertainty in designing a definite trial. We therefore believe that a group sequentind design is appropriate given the lack of evidence currently available. We believe that this is the idenl trinl design becnuse it enables us to present the maximum size of trinl that is needed, nlongside a flexible group sequential nppronch that allows the trial to terminate enrly for one of two scenarios. The first scenario is overwhelming evidence of benefit (due perhaps to a large treatment effect and/or less variability in the outcome mensure). The second scenario is due to a suitnbly defined futility - that is, luaving got a certain way to the maximum trinl size, we are confident that a large treatment effect is implausible, and that the current estimate of the treatment effect is sufficiently precise to be convincing, nllowing the trial to terminnte early.

\subsection{Group Sequential Design}

Following detailed discussions with the DMC, we will use a Lan-DeMets alphn spending appronch [1] with OBrien Fleming boundaries [2], as a two-sided test, with efficacy and futility boundaries. There will be 5 interim evaluations, equally spaced at 215, 429, 644, 858 and 1073 participants. With the O'Brien Fleming boundaries, there is the possibility of stopping early at the 215 and 420 looks for example, but only for very strong evidence (either wny) and if there is still the need to go to full trial size the ability to determine a treatment effect near the $5 \%$ level of significance by 'wasting the alplas' in pointless enrly evaluations will not be compromised.

The genernl form of the group sequentinl design is; participants are randomised between two trentment groups, experitmentnl (GTN spray) and a comparator (placebo). At the $i^{\text {th }}$ interim aunlysis, when the required number of participant responses have been observed the test statistic is calculated. If this statistic crosses the pre-specified boundnries, the trinl can be stopped either to reject the null hypothesis or fril to reject the null lypothesis. For this study, it is possible to stop for efficacy at all of the interim evaluntions, lowever only at the $3^{\text {rd }}$ and last for futility: Figure 1 summarises the design. 
Figure 1. Group sequential design

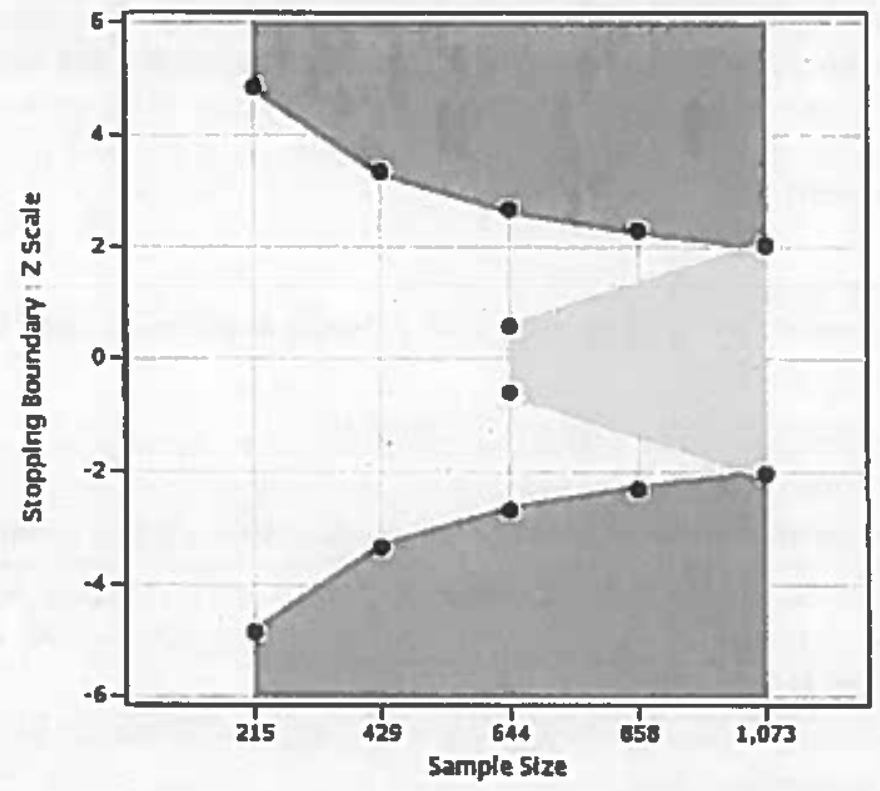

\subsection{Randomisation and Blinding}

Randomisation packs will be ordered from pharmacy and kept on the labour ward. Study drugs will be provided to site pharmacies in pre-packed randomised, permuted blocks. Once a participant is recruited the study drug will be allocated by taking the next available trentment pack from the shelf. The study will be performed double masked so neither the patient nor the investigator will know which treatment has been allocuted. Breaking of the study masking will only be performed where knowledge of the treatment is absolutely necessary for safe management of the patient.

Central unblinding procedures will be maintained by the Centre for Healthcare Randomised Trials (CHaRT) who will hold the randomisation list for the trial. Unblinding (emergency or otherwise) can be carried out by a senior clinicinn (normally a consultant). The senior clinicinn will call an Internctive Voice Response System (IVRS) and enter their name, the reason for unblinding, and the study drug number into the automated system. This phone line will be available at all times. The unblinding will be recorded on the trial databrse and the trial mannger will be informed. Unless there is a clinical requirement, the masking will not be broken until after data entry is complete, the validity of the datn is checked, all queries resolved and the patient populations agreed.

\section{Outcome Measures}

\subsection{Primary outcome}

- Clinical: need for MROP, defined as the placenta remaining undelivered 15 minutes post study treatment and/or being required within 15 ininutes of trentment due to safety concerns. 
- Safety: measured blood loss between administrntion of treatment and transfer to the postnatal ward or other clinical area (e.g. Habour ward high dependency)

- Patient-centred: sntisfaction with trentuent and side effect profile assessed by questionnaire. It will be based on qualitative studies and previously used questionnaires to assess satisfaction [3] .

\subsection{Secondary outcomes}

- Clinical:

$i$ i. Fall in haemoglobin of more than $15 \%$ between recruitment and the first postnatal dny

ii Time from randomisation to delivery of placenta

iji MROP in thentre

iv Need for earlier than plamed MROP on the basis of the clinical condition

v Fall in systolic or dinstolic blood pressure of more than $15 \mathrm{mmHg}$ and/or increase in pulse of more than 20 bents/minute between bnseline and 5 and 15 uinutes postadministration of active/placebo treatment.

vi Need for blood transfusion between time of delivery and discharge from hospital

vii Need for general annestliesia

viii Mnternal pyrexia (one or more temperature readings of more than $38 \mathrm{C}$ within 72 lirs of delivery or disclinge from hospital if discharge occurs sooner)

ix Sustained uterine relaxation after removal of placenta using uterotonics.

\subsection{Timing of outcome measurements}

\begin{tabular}{|c|c|c|c|c|c|c|c|}
\hline & Bustim & $\begin{array}{l}\text { Ruudcunitsu- } \\
\text { tlou }\end{array}$ & T) 14umles" & 15 tolisuttest & $\begin{array}{l}\text { Biflutit } \\
\text { trussiter }\end{array}$ & $\begin{array}{l}\text { Dufure" } \\
\text { distolinurge" }\end{array}$ & fi niviks \\
\hline $\begin{array}{l}\text { Br, pultis, } \\
\text { temupluture }\end{array}$ & 8 & & $\checkmark$ & $\checkmark$ & & & \\
\hline Full biond c cuut. & $\checkmark$ & & & & & $\checkmark$ & \\
\hline 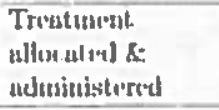 & & 8 & & & & & \\
\hline Dloxsd lonis & & & & & $\checkmark$ & & \\
\hline Nevd fur alnop & & & & $\checkmark$ & & & \\
\hline 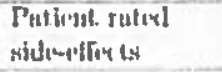 & & & & & & $\checkmark$ & $\checkmark$ \\
\hline $\begin{array}{l}\text { Putionat rutod } \\
\text { sutisfint liont }\end{array}$ & & & & & & 7 & $\checkmark$ \\
\hline Adve'tse " ate luts & & & & & & $r$ & $\checkmark$ \\
\hline
\end{tabular}

- posat alminiatration of otuly drue

\subsection{Adverse events}

An adverse event (AE) is nny untoward medical occurrence in a clinical trial participant which does not necessarily hnve a callsal relationslup with ut investigntionnl medicinal product (IMIP). 
An adverse reaction (AR) is any untoward nud unintended response to an IMP which is related to nny dose administered to that participant.

A serious adverse event (SAE), serious adverse reaction (SAR) is any AE or AR, that at any dose:

- results in denth of the clinjeal trial participant;

- is life threntening";

- requires in-patient hospitnlisation ${ }^{\dagger}$ or prolongation of existing loospitalisation;

- results in persistent or significant disalility or incnpacity;

- consists of a congenital nmomaly or birth defect;

- results in any other significant medicnl event not meeting the criteria above.

- Life-threatening in the definition of an SAE or SAR sefers to an event where the pnrticipant was at risk of death at the time of the event. It does not refer to an event which hypothetically might lave caused denth if it were more severe.

I Any hospitalisation that was planned prior to randomisation will not meet SAE criteria. Any' hospitalisntion that is planned post-randornisation will meet the SAE criteria.

Participants will be asked about the occurrence of AE/SAEs prior to discharge from the hospital and in the 6 week postnatal questionnnire. These will be summarised and presented.

\section{Sample Size and Power Calculations}

We believe that a $10 \%$ decrense of women needing manual removal of the placenta will be sufficient advantage to change clinical practice and result in the widespread uptake of this simple, safe and clicap drug intervention (2 puffs $(800 \mathrm{~g})$ sublingual GTN sprny administered within minutes of n diagnosis of suspected retnined placenta). From a statisticnl perspective, the maximum variability in a binary outcome (need for surgical intervention yes or no) occurs at a $50 \%$ rate in the placebo spray arm. On a fixed sample appronch at $\mathbf{9 0 \%}$ power and $5 \%$ level of significance, this would need 1038 women (519 in each group) to demonstrnte a $10 \%$ change from $50 \%$ on placebo to $40 \%$ on GTN spray. Since the outcorne is recorded within minutes of the intervention on the hospital systems (surgery took place yes/no), we anticipate mininnal (if nny) loss to follow up. So we can be confident that there is no need for a trinl larger than this, except for the need for a small uplift to a possible mnximum of 1073 women to allow for the multiple sequential evaluations of the dntn, to reliably answer this question.

\section{Statistical Methods}

The statistical annlysis will be brsed on all participants as randomised, irrespective of sulsequent coniplince with the trentment allocnted (i.e. following the intention-to-trent principle). Therelore nl participants will remain in their allocated group for analysis.

Statistical significunce will be at the $5 \%$ level with corresponding $95 \%$ confidence intervals (CI) derived. 
Treatment groups will be described at baseline and follow-up using menns (with standard devintions), medians (with inter-qunrtile ranges) and numbers (with percentnges) where npproprinte.

The interim analyses for the DMC will be specified within their DMC Charter, and results of these interim analyses will be in strict confidence (no member of the research team apart from the study statistician will be aware of the contents of these analyses). Advice on the final sample size will be revealed to the Trial Steering Committec (TSC).

\subsection{Primary outcomes}

The primary clinical autcome of nced for MIROP will be usulysed using logistic regression, and odds ratios of the treatment effect, together with $95 \%$ CIs and associated likelihood ratio P-value, will be estimated. Other primary outcones will be annlysed using generalised linenr models appropriate to the distribution of ench outcome and inchuding centre as a random effect. These models will adjust for relevant baseline fnctors.

\subsection{Secondary outcomes}

Secondary outcomes will be analysed using the approprinte generalised linear model as for the primary outcomes, using $5 \%$ significance level, nnd corresponding $95 \%$ Cls will be derived.

\subsection{Subgroup analyses}

Planned subgroup annlyses are intended to explore potential effect modjications of previous Csection and gestation nt delivery ( $<36$ and $\geq 30$ weeks gestntion). A stricter level of statistical significnnce will be applied ( $1 \%$ with $99 \%$ Cl derived).

\subsection{Missing Data}

Sensitivity analyses will assess the robustness of the findings to nny missing dntn. However for the primary clinical outcome this is expected to be virtually nil, as the outcome is measured within minutes of taking the intervention. 


\section{Dummy Tables}

Tnlsle 1. Recruitment by centre $-\mathbf{n}(\%)$

\begin{tabular}{lll}
\hline Centre & GTN spray & Placebo \\
\hline Edinburgh & \\
Glasgow & \\
Mancliester & \\
. \\
.
\end{tabular}


Trable 2. Buseline characteristics

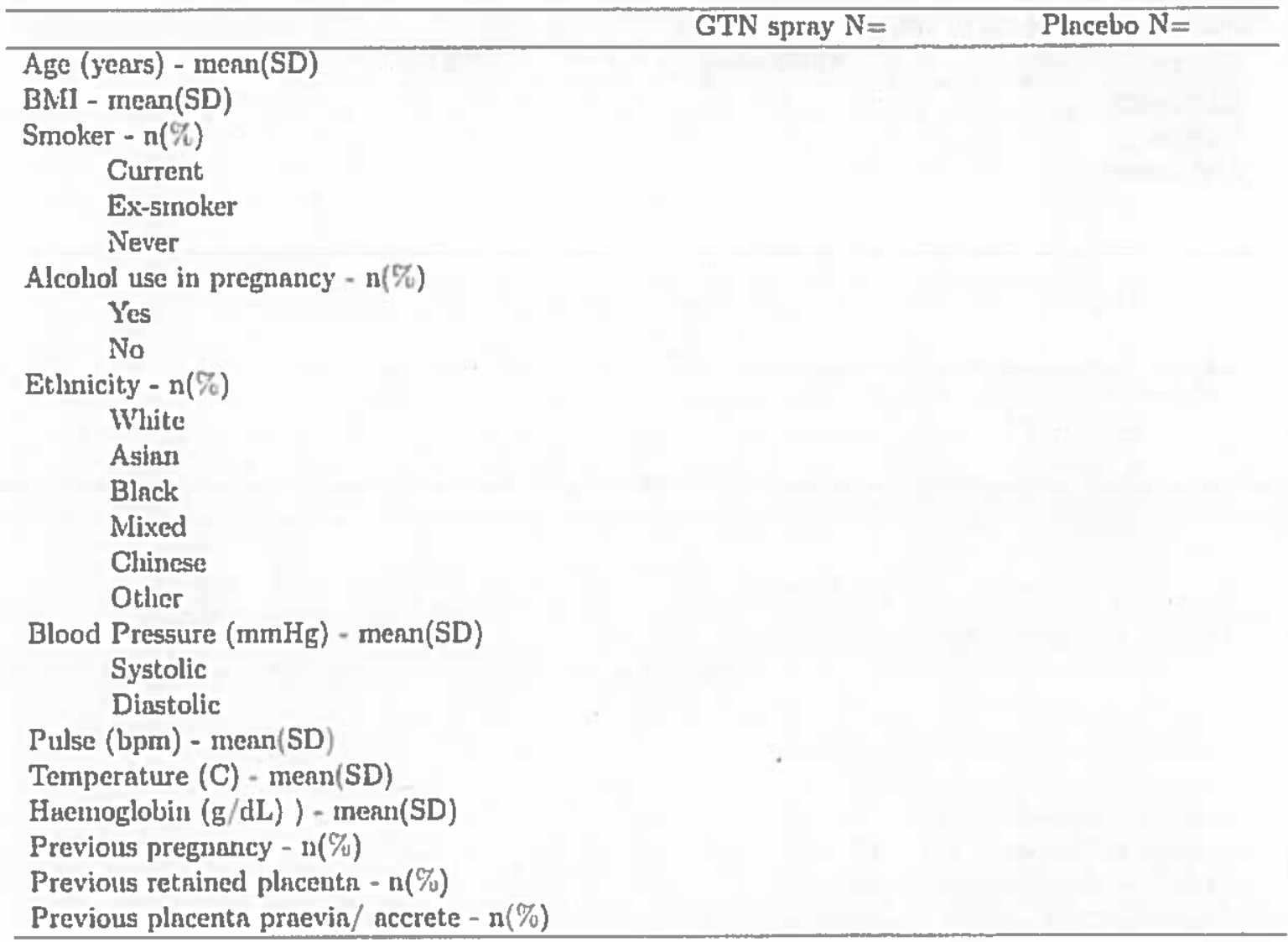

Table 3. Primnry clinical outcome of need for MROP at 15 minutes post ndministration of study drug

\begin{tabular}{cccccc}
\hline & $\begin{array}{c}\text { GTN spray } \\
\mathrm{N}=\end{array}$ & $\begin{array}{c}\text { Placebo } \mathrm{N} \\
=\end{array}$ & Odds ratio & 95\% CI & p-vilue \\
\hline
\end{tabular}

Praportion of wotnen needing

MIROP $-\mathbf{n}(\%)^{1}$

Defined as proportion of women needing MROP bechuse the placenta remains undelivered is minutes post study treat ment und/or is requirud within 15 minutes of treatunemt due to safety concerns.

Table 4. Primary snfety outcome of blood loss between administration of trentment and transfer to postnatal ward or other clinical aren

\begin{tabular}{|c|c|c|c|c|c|}
\hline & $\begin{array}{c}\text { GTN sprky } \\
\mathrm{N}=\end{array}$ & $\begin{array}{c}\text { Placebo N } \\
=\end{array}$ & Odds ratio & $95 \% \mathrm{Cl}$ & p-value \\
\hline $\begin{array}{c}\text { Blood loss }(\mathrm{ml})-n(\%) \\
<500 \\
500-1000 \\
>1000\end{array}$ & & & & & \\
\hline
\end{tabular}


Table 5. Primary patient-sided outcome of sntisfaction with trentment before disclinge and at $G$ weeks

\begin{tabular}{|c|c|c|c|c|c|}
\hline & $\begin{array}{c}\text { GTN spray } \\
\mathrm{N}=\end{array}$ & $\begin{array}{c}\text { Placebo } \\
N=\end{array}$ & Odds ratio & $95 \% \mathrm{CI}$ & p-value \\
\hline $\begin{array}{l}\text { Would you recommend this } \\
\text { trentment (study drug) to a } \\
\text { friend/relntive? - } n(\%) \\
\text { Dischnrge } \\
6 \text { weeks }\end{array}$ & H. & & & & \\
\hline
\end{tabular}

Tnble 6. Primary patient-sided outcome of side effect profite before dischnrge and at 6 weeks

\begin{tabular}{|c|c|c|c|c|c|}
\hline & $\begin{array}{c}\text { GTN spray } \\
N=\end{array}$ & $\begin{array}{c}\text { Placebo } \\
\mathrm{N}=\end{array}$ & Odds rntio & $95 \% \mathrm{CI}$ & p-value \\
\hline \multicolumn{6}{|l|}{ Feeling sick $-\mathbf{n}(\%)$} \\
\hline \multicolumn{6}{|l|}{ Discharge } \\
\hline \multicolumn{6}{|l|}{6 weeks } \\
\hline \multicolumn{6}{|l|}{ Palpitations/henrt racing $-\mathrm{n}(\%)$} \\
\hline Disclinge & & & & & \\
\hline 0 weeks & & & & & \\
\hline
\end{tabular}

Table 7. Secondary clinical outcomes

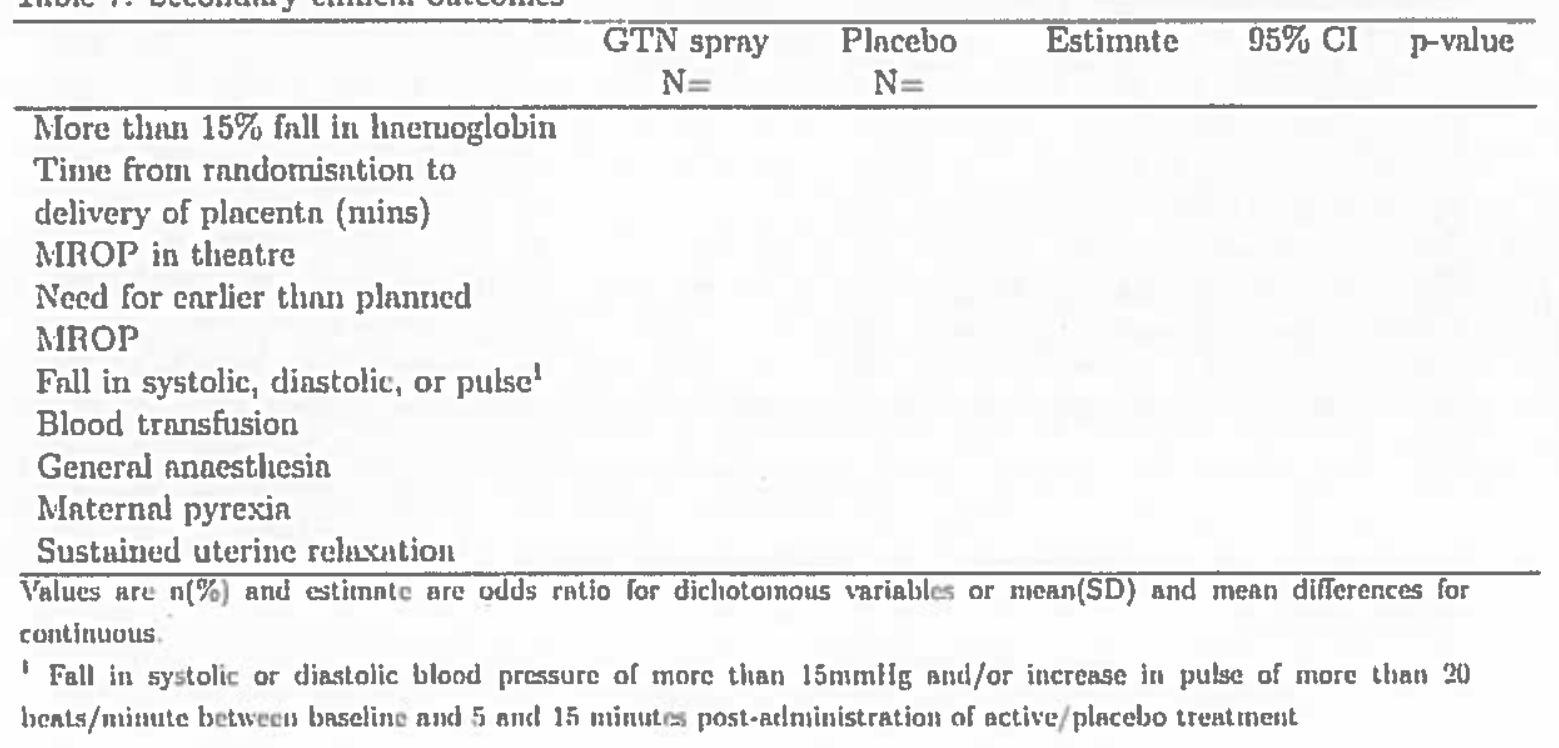

\section{References}

[1] K. K. G. LAN and D. L. DeMets. Discrete sequentind boundaries for clinicnl trinls. Biometrika, 70 (3):659-663, 1983. doi: 10.1093/biomet/70.3.659.

[2] Peter C. O'Brien and Thomns R. Fleming. A multiple testing procedure for clinical trials. Biometrics, 35(3):540-550. 1979.

3. SS Bollnprngndn, F MacKenzie, JD Norrie, O Eddamn, S Petrou, M Reid, and JE Norman. Randomised placebo controlled trinl of outpntient (at home) cervicnl ripening with isosorbide 
mononitrate (IMN) prior to induction of Inbour - clinicnl trinl with analyses of efficacy nnd neceptability. the IMIOP study. BJOG: An International Journal of Obstetrics and Gynnecology, 11G(9):1185-115, 2009. doi: 10.1111/j.1471-0528.2009.02216.x. 